Niels P. R. Anten · Tadaki Hirose

\title{
Limitations on photosynthesis of competing individuals in stands and the consequences for canopy structure
}

Published online: 16 October 2001

(C) Springer-Verlag 2001

\section{Oecologia (2001) 129:186-196}

In the print version, the following errors occurred:

1. In the caption of Fig. 5 the subscript and supercripts appeared in the wrong format: $\left(P^{*} \ldots \ldots \ldots \mathrm{D}\right.$ should read $\left(P^{*}{ }^{-} P_{D}\right) / P_{D}$.

2. The quantum yield was left out of Eq. 7, which should read:

$P_{L}=\frac{\left(P_{m}+\phi I_{L}\right)-\left[\left(P_{m}+\phi I_{L}\right)^{2}-4 \phi \theta P_{m} I_{L}\right]^{0.5}}{(2 \theta)}-R_{d}$

The online version of the original article can be found at http://dx.doi.org/10.1007/s004420100718

N.P.R. Anten $(\varpi) \cdot$ T. Hirose

Biological Institute, Graduate School of Science,

Tohoku University, Aoba, Sendai 980-8578 Japan

Present address:

N.P.R. Anten, Department of Plant Ecology, Utrecht University, PO Box 800.84 3508TB Utrecht, The Netherlands,

e-mail: anten@life.biology.tohoku.ac.jp, Fax: +31-30-2541319 